\title{
Influência do volume por árvore e da distância de extração no desempenho do skidder em povoamentos de eucalipto
}

\section{Influence of volume per tree and extraction distance on skidder performance in eucalyptus stands}

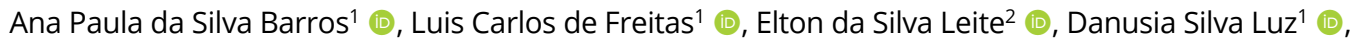 \\ Liniker Fernandes da Silva ${ }^{2}$ (1), Breno Santana Sena ${ }^{1}$ (1) , Jeverson Cruz Santos ${ }^{1}$ (1) \\ 1 Universidade Estadual do Sudoeste da Bahia - UESB, Vitória da Conquista, BA, Brasil \\ ²Universidade Federal do Recôncavo da Bahia - UFRB, Cruz das Almas, BA, Brasil
}

Como citar: Barros, A. P. S., Freitas, L. C., Leite, E. S., Luz, D. S., Silva, L. F., Sena, B. S., \& Santos, J. C. (2021). Influência do volume por árvore e da distância de extração no desempenho do skidder em povoamentos de eucalipto. Scientia Forestalis, 49(131), e3612. https://doi.org/10.18671/scifor.v49n131.19

\begin{abstract}
Resumo
Analisar variáveis que influenciem a produtividade das máquinas é de fundamental importância para o planejamento e sustentabilidade da colheita florestal, principalmente na extração onde os custos são elevados. Objetivou-se com este trabalho realizar uma avaliação técnica e econômica na atividade de extração de árvores inteiras com uso do trator florestal skidder. Tecnicamente avaliou-se os elementos do ciclo operacional, disponibilidade mecânica, eficiência operacional e produtividade em povoamentos de eucalipto no litoral norte da Bahia. Na análise econômica avaliou-se os custos de produção em função de duas classes de produtividades e diferentes distâncias de extração. O aumento da distância de extração e a produtividade dos povoamentos influenciam no ciclo operacional, sendo o arraste o elemento com maior demanda de tempo. O custo operacional mostrou-se expressivo (U\$S 136,25 he- ${ }^{-1}$ ), entretanto, a alta performance do skidder proporcionou baixos custos por metro cúbico extraído (U\$S 1,44 e US\$1,07 $\mathrm{m}^{3}$ ). Os resultados mostraram que menores distâncias de extração e talhões de maiores produtividades condicionaram custos sustentáveis para a atividade de colheita florestal.
\end{abstract}

Palavras-chave: Custos de extração; Máquina florestal; Produtividade.

\begin{abstract}
Analyzing the operational variables that influence machines' productivity is of significant importance for the planning and sustainability in timber harvesting activity, mainly due to high costs. The objective of this paper was to carry out a technical and cost assessment in timber extraction by a skidder machine considering the whole tree system. The technical analysis involved operational cycle, mechanical availability, operational efficiency and machine productivity in a eucalyptus plantation on the northern coast of Bahia. In the economic analysis the production costs according to two levels of forest productivity and different distances of extraction were evaluated. It was found that the extraction distance and productivity levels in the plots influenced the operating cycle time. The operating costs for the skidder machine was of U\$S 136.25 he $^{-1}$, however the high performance in the timber extraction activity conditioned lower costs per cubic meter (U\$S 1.44 and US $\$ 1.07 \mathrm{~m}^{3}$ ). The results showed that shorter distances of extraction and high productivity plots have provided sustainable costs in the timber harvesting activity.
\end{abstract}

Keywords: Extraction costs; Forest machine; Productivity.

Fonte de financiamento: Coordenação de Aperfeiçoamento de Pessoal de Nível Superior.

Conflito de interesse: Nada a declarar.

Autor correspondente: apsbarros21@gmail.com

Recebido: 12 setembro 2020.

Aceito: 25 fevereiro 2021

Editor: Paulo Henrique Müller Silva.

(c) (i) Este é um artigo publicado em acesso aberto (Open Access) sob a licença Creative Commons Attribution, que permite uso, distribuição e

c) reprodução em qualquer meio, sem restrições desde que o trabalho original seja corretamente citado. 


\section{INTRODUÇÃO}

A mecanização favoreceu a produtividade no setor florestal, o que proporcionou o Brasil alcançar uma receita total de $\mathrm{R} \$ 86,6$ bilhões com participação de 1,3\% do PIB e 6,9\% do PIB industrial, em uma área de florestas plantadas de 7,83 milhões de hectares, crescendo 13,1\% em relação a 2017 (Indústria Brasileira de Árvores, 2019).

Este crescente aumento foi impulsionado a partir de 1994 onde ocorreu a expansão da mecanização da colheita florestal, oferecendo melhorias das condições de trabalho e redução nos custos de produção (Machado et al., 2014).

$\mathrm{Na}$ colheita de madeira, destaca-se a operação de extração, que consiste na remoção da madeira, na forma de toras, fustes ou árvores inteiras, do interior do povoamento para a margem do talhão, estrada ou pátio intermediário (Lopes \& Diniz, 2015). As operações de colheita florestal são bastante complexas, devido a interação de inúmeros fatores técnicos, econômicos, ambientais e ergonômicos que, atuando em conjunto ou isoladamente, interferem de forma dinâmica nas condições operacionais (Machado \& Lopes, 2008).

De modo geral, a capacidade operacional das máquinas florestais é potencialmente afetada por diversas variáveis, como: volume médio individual por árvore e a distância de extração (Santos et al., 2013; Leite et al., 2014). Os estudos na área promovem o máximo aproveitamento das funções da máquina com o aperfeiçoamento das técnicas de operações (Pereira et al., 2015), sendo um processo contínuo de melhoria da colheita mecanizada (Simões \& Fenner, 2010; Leite et al., 2014).

As avaliações de produtividade e de custos de máquinas em situação real é de fundamental importância, possibilitando subsidiar maior sustentabilidade do processo produtivo (Pereira et al. 2015). Estudo da otimização das atividades que compõem o custo operacional de máquinas florestais pode resultar em uma economia de cerca de $7 \%$ no custo final do metro cúbico de madeira (Silva et al., 2014).

Apesar de um padrão já conhecido de maquinários que operam nos processos de colheita florestal, inovações frequentes como tecnologias embarcadas (Lordelo, 2012), capacidade de operar em terrenos acidentados (Robert et al., 2013), dentre outras mudanças, projetam maquinários com cenários cada vez mais distintos em termos de custos e rendimentos operacionais. Em virtude desses processos de inovações, estudos realizados nesta área acabam necessitando de atualizações constantes sob o ponto de vista técnico e econômico de forma auxiliar o planejamento e as tomadas de decisões no processo da colheita florestal.

Neste contexto, objetivou-se com este trabalho avaliar o efeito da distância de extração e do volume médio por árvore no desempenho técnico e econômico de um skidder em povoamentos de eucalipto.

\section{MATERIAL E MÉTODOS}

A pesquisa foi desenvolvida em área de produção florestal pertencente a uma empresa produtora de carvão vegetal, no município de Entre Rios no litoral norte da Bahia, situado na coordenada central $11^{\circ} 57^{\prime} 58.4^{\prime \prime} \mathrm{S}$ e $38^{\circ} 09^{\prime} 53.3^{\prime \prime}$ W.

A região apresenta clima tropical úmido (Af), segundo a classificação climática de Köppen (Alvares et al. 2013). Os valores médios de altitude, temperatura e precipitação são de $162 \mathrm{~m}$, $23,9^{\circ} \mathrm{C}$ e $1.495,7 \mathrm{~mm}^{\mathrm{ano}}{ }^{-1}$, respectivamente, com período chuvoso de fevereiro a agosto (Superintendência de Estudos Econômicos e Sociais da Bahia, 2010). O solo predominante foi classificado como Argissolo Amarelo distrocoeso típico, com textura média (Banco de dados da empresa). $\mathrm{O}$ estudo contemplou dois povoamentos distintos de Eucalyptus grandis $\mathrm{x}$ E. urophylla, com volumes individuais por árvore de 0,257 (povoamento 1) e 0,329 $\mathrm{m}^{3}$ (povoamento 2), resultando em uma produtividade de 286,00 e 345,21 $\mathrm{m}^{3} \mathrm{ha}^{-1}$, respectivamente (Tabela 1). 
Tabela 1. Características dos povoamentos de Eucalyptus grandis x Eucalyptus urophylla.

\begin{tabular}{ccc}
\hline Variáveis & Povoamento (1) & Povoamento (2) \\
\hline Idade de corte (meses) & 84 & 96 \\
Espaçamento $(\mathrm{m})$ & $4,0 \times 2,25$ & $4,5 \times 2,0$ \\
DAP médio e desvio $(\mathrm{cm})$ & $14,4 \pm 3,57$ & $15,0 \pm 3,47$ \\
Altura e desvio $(\mathrm{m})$ & $21,90 \pm 2,10$ & $22,2 \pm 2,14$ \\
VMI $\left(\mathrm{m}^{3}\right)$ & 0,257 & 0,329 \\
Volume médio com casca $\left(\mathrm{m}^{3} \mathrm{ha}^{-1}\right)$ & 286,00 & 345,21 \\
\hline
\end{tabular}

Em que: DAP = diâmetro à 1,3 $\mathrm{m}$ do solo; VMI = Volume Médio por Árvore $\left(\mathrm{m}^{3}\right)$.

O sistema de colheita empregado foi o de árvores Inteiras (full-tree), em que as árvores foram cortadas e derrubadas pelo feller-buncher e, em seguida, extraídas até as margens das estradas com auxílio do skidder.

O desgalhamento foi realizado pelo skidder, equipado com um implemento, desgalhador frontal, acoplado ao braço hidráulico do trator, para movimentação de subida e descida, composto por discos planos recortados e de movimentação rotativa. O traçamento e empilhamento das árvores foram executados com auxílio de uma garra traçadora.

Utilizou-se o skidder da fabricante Caterpillar, modelo 555, motor Caterpillar C7.1 ACERT,

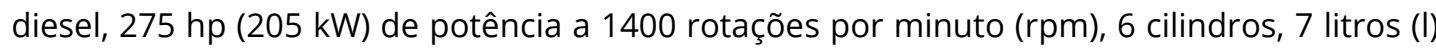
de cilindrada, tração nas quatro rodas $(4 \times 4)$, podendo atingir até $20 \mathrm{~km} \mathrm{~h}^{-1}$, garra hidráulica com área de $2,04 \mathrm{~m}^{2}$ e rotação $360^{\circ}$ e alcance de $3,0 \mathrm{~m}$, com lâmina frontal de 3,2 m de largura e altura de levante de 1,4 m, com massa de $22.128 \mathrm{~kg}$ (Caterpillar, 2015).

O skidder realizava o arraste das árvores do interior dos talhões até as margens das estradas com um efetivo de dois operadores, um para cada turno, totalizando 17,5 horas diárias.

O skidder totalizou $88 \mathrm{~h}$ de atividade, com 60 horas trabalhadas efetivamente. As paradas mecânicas foram de $12 \mathrm{~h}$ e as paradas operacionais totalizaram $18 \mathrm{~h}$. Todas as interrupções foram constituídas na sua totalidade durante o período de coleta de dados.

Tecnicamente avaliou-se os elementos do ciclo operacional, disponibilidade mecânica, eficiência operacional e produtividade na operação do skidder. O ciclo operacional contemplou as seguintes etapas: Deslocamento sem carga - referiu-se ao deslocamento da máquina das margens das estradas até os feixes de árvores, localizados no interior do talhão; Manobra e carregamento - iniciou-se com a manobra, abertura da garra e carregamento dos feixes, repetindo por 3, 4 ou 5 vezes até completar a carga; Arraste - iniciou-se com o deslocamento da carga parcialmente suspensa até próximo às pilhas de árvores, na margem da estrada; Manobra e descarregamento - iniciou-se com a realização das devidas manobras e posicionamento do feixe, perpendicularmente ao eito de trabalho, sendo esta etapa finalizada com o acionamento da garra e liberação do feixe de madeira.

No ciclo operacional foi mensurado a quantidade de toras carregadas por ciclo e os tempos em que a máquina não estava realizando as atividades descritas, chamada de interrupções operacionais. As interrupções foram classificadas em mecânicas (manutenções preventivas, incluindo abastecimentos) e não mecânicas (refeições dos operadores e necessidades pessoais), estimando as pausas técnicas e pessoais, respectivamente.

No estudo do ciclo operacional do skidder, utilizou-se o método de tempo contínuo em segundos, ou seja, o tempo de cada elemento foi obtido por subtração, sem detenção do cronômetro, por ocasião do curto espaço de tempo entre os elementos.

Para estimar a quantidade de amostras necessárias, foi realizado preliminarmente um estudo piloto com 20 ciclos operacionais do skidder para cada povoamento (Equação 1), conforme metodologia proposta por Barnes (1977). Em seguida determinou o número mínimo de ciclos que atendessem um erro de amostragem admissível máximo de 5\%, com $95 \%$ de probabilidade. Os ciclos operacionais práticos foram superiores aos estimados. 
$\mathrm{n} \geq \frac{\mathrm{T}^{2}+\mathrm{CV}^{2}}{\mathrm{E}^{2}}$

em que: $\mathrm{n}$ = número mínimo de ciclos operacionais necessários; $\mathrm{t}$ = valor de $\mathrm{t}$, para o nível de probabilidade desejado e (n -1) graus de liberdade; CV = coeficiente de variação em percentagem; $\mathrm{E}$ = erro de amostragem admissível a 95\% de probabilidade.

As velocidades de deslocamento do skidder foram obtidas por meio da razão entre a distância de deslocamento em metros e o tempo em segundos. Para coleta de dados foram utilizados distanciômetro e cronômetros centesimais.

A produtividade operacional do skidder foi estimada em metros cúbicos de madeira extraída por hora efetiva de trabalho, para tal utilizou-se a fórmula proposta por Simões (2008), conforme Equação 2:

$\mathrm{P}=\frac{\mathrm{V}}{\mathrm{T}} * \mathrm{e}$

em que: $\mathrm{P}=$ rendimento operacional médio $\left(\mathrm{m}^{3} \mathrm{~h}^{-1}\right) ; \mathrm{V}=$ volume médio, em metros cúbicos de madeira arrasta com casca por ciclo operacional $\left(\mathrm{m}^{3}\right) ; \mathrm{T}=$ tempo médio em horas efetivas de trabalho necessário para completar o ciclo operacional (h); e = eficiência operacional (\%).

O volume médio de madeira extraída por ciclo foi obtido multiplicando-se o número de árvores arrastadas em cada ciclo pelo seu volume médio, de acordo com cada povoamento (1 e 2).

A disponibilidade mecânica foi calculada a partir da Equação 3 e estimada em porcentagem de tempo que a máquina está mecanicamente apta para o desempenho de suas funções (Birro et al., 2002).

$\mathrm{DM}=\frac{(\mathrm{HT}-\mathrm{TPM})}{\mathrm{HT}} \mathrm{x} 100$

em que: $\mathrm{DM}=$ grau de disponibilidade mecânica (\%); TPM = tempo de permanência em manutenção $(h) ; H T$ = horas totais $(h)$.

A eficiência operacional foi mensurada pela razão do tempo em que a máquina se encontrava em atividade e o tempo total programado para o trabalho (Equação 4) (Leite et al., 2014):

$\mathrm{EO}=\frac{(\mathrm{He})}{(\mathrm{He}+\mathrm{Hp})} \times 100$

em que: $\mathrm{EO}=$ eficiência operacional (\%); He = horas efetivas de trabalho (h); $\mathrm{Hp}=$ horas paradas (h).

Os custos horários operacionais foram estimados de acordo com a metodologia proposta pela American Society of Agricultural Engineers (2001). O custo operacional foi expresso em dólar (americano) por hora efetiva de trabalho (US\$ he ${ }^{-1}$ ) e a taxa de câmbio $\mathrm{U} \$ 1,00=\mathrm{R} \$ 5,387$, cotado no dia 05/02/21. A taxa de juros utilizada foi de 7\% a.a.

O custo de produção foi estimado em dólares por metro cúbico extraído (US $\$ \mathrm{~m}^{-3}$ ), sendo calculado conforme a Equação 5.

$\mathrm{Cp}=\frac{\mathrm{Co}}{\mathrm{P}}$ 
em que: $\mathrm{Cp}=$ custo de produção $\left(\right.$ US $\left.\$ \mathrm{~m}^{-3}\right) ; \mathrm{Co}=$ custo operacional $\left(\right.$ US $\$$ he-1 $\left.{ }^{-1}\right) ; \mathrm{P}=$ produtividade $\left(m^{-3} h^{-1}\right)$.

Os tempos de deslocamento sem carga e deslocamento com carga do skidder nos dois povoamentos foram analisados pela modelagem de regressão em função das distâncias de extração. A análise de regressão foi aplicada para produtividade $\left(\mathrm{m}^{3} \mathrm{~h}^{-1}\right)$ e custo de produção (US\$ $\mathrm{m}^{-3}$ ) em função da distância de extração $(m)$, sendo projetada para os dois povoamentos em estudo. Utilizou-se os critérios de escolha dos melhores modelos: os coeficientes de determinação ajustados em porcentagem $\left(R^{2}{ }_{a j} \%\right)$, erro padrão da estimativa em porcentual (Syx\%) e análise gráfica dos resíduos porcentuais e facilidade de aplicação.

Os tempos médios das etapas do ciclo operacional do skidder foram submetidos aos testes de Liliefors e Bartlett para verificação da normalidade e homogeneidade de variâncias, respectivamente.

As médias comparadas pelo teste " $\mathrm{t}$ " de student para amostras independentes para os dois povoamentos florestais. Os desdobramentos do teste de média e regressão, foram realizados após comprovada significância da análise de variâncias. A composição porcentual dos tempos dos ciclos operacionais e o custo horário foram apresentados graficamente a partir de análise descritiva, desconsiderando as interrupções.

\section{RESULTADOS E DISCUSSÃO}

Neste estudo foram coletados 110 ciclos para o Povoamento 1 e 87 ciclos para o Povoamento 2, valores superiores aos estimados, 98 e 72 para os povoamentos 1 e 2 , respectivamente. As médias de tempo para um ciclo operacional foram de 76 e 69 segundos, respectivamente para os povoamentos 1 e 2 (Tabela 2).

Tabela 2. Tempos médios do ciclo operacional do skidder para os povoamentos (1) e (2).

\begin{tabular}{ccc}
\hline & \multicolumn{2}{c}{ Povoamentos } \\
\cline { 2 - 3 } Amostragem Estatística & $\mathbf{( 1 )}$ & (2) \\
\hline Média (seg.) do ciclo total do skidder & 76,00 & 69,40 \\
Intervalo de confiança (IC) da média (seg.) & 2,89 & 4,46 \\
Limite inferior do IC (seg.) & 73,11 & 64,97 \\
Limite superior do IC (seg.) & 78,89 & 73,89 \\
Coeficiente de variação (CV\%) & 24,96 & 21,21 \\
Número de árvores quantificadas & 783 & 913 \\
Volume total de madeira (m ${ }^{3}$ ) & 201,23 & 300,38 \\
Volume médio individual por árvore $\left(\mathrm{m}^{3}\right)$ & 0,257 & 0,329
\end{tabular}

Os ciclos operacionais dos povoamentos 1 e 2 compreenderam pelo arraste médio de 14 e 15 fustes, respectivamente. As maiores diferenças entre os elementos do ciclo operacional dos povoamentos foram o percentual do arraste e de manobra e descarregamento (Figura 1), considerando a distância média de extração de 109 metros. O elemento de arraste evidenciou as maiores diferenças entre os povoamentos, sendo que o povoamento 1 obteve menor percentual do tempo gasto, o que foi proporcionado pelo menor volume médio individual das árvores $\left(0,257 \mathrm{~m}^{3}\right)$. 
(1)

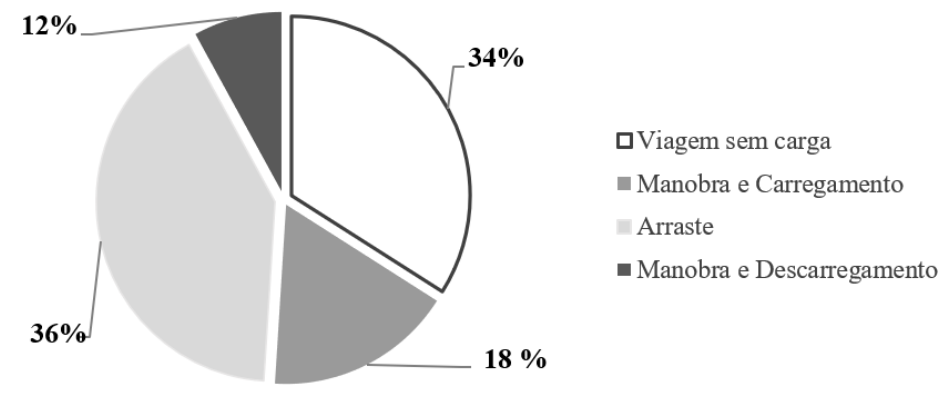

(2)

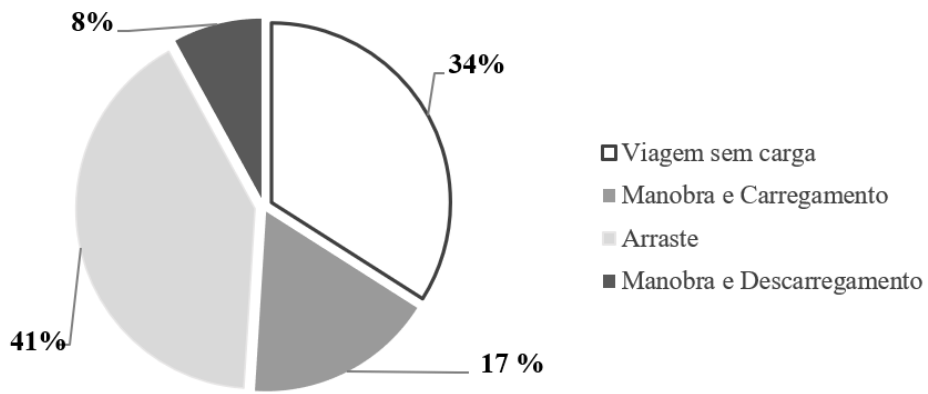

Figura 1. Composição porcentual do tempo do ciclo operacional do skidder para os povoamentos 1 e 2.

Os tempos de deslocamento do skidder sem carga para o povoamento 1 apresentaram maior inclinação da reta, evidenciando ser mais sensível ao aumento do tempo com o aumento da distância de extração (Figura 2). Isto pode estar fundamentado nas diferenças dos povoamentos, como o volume médio por árvore e espaçamento.
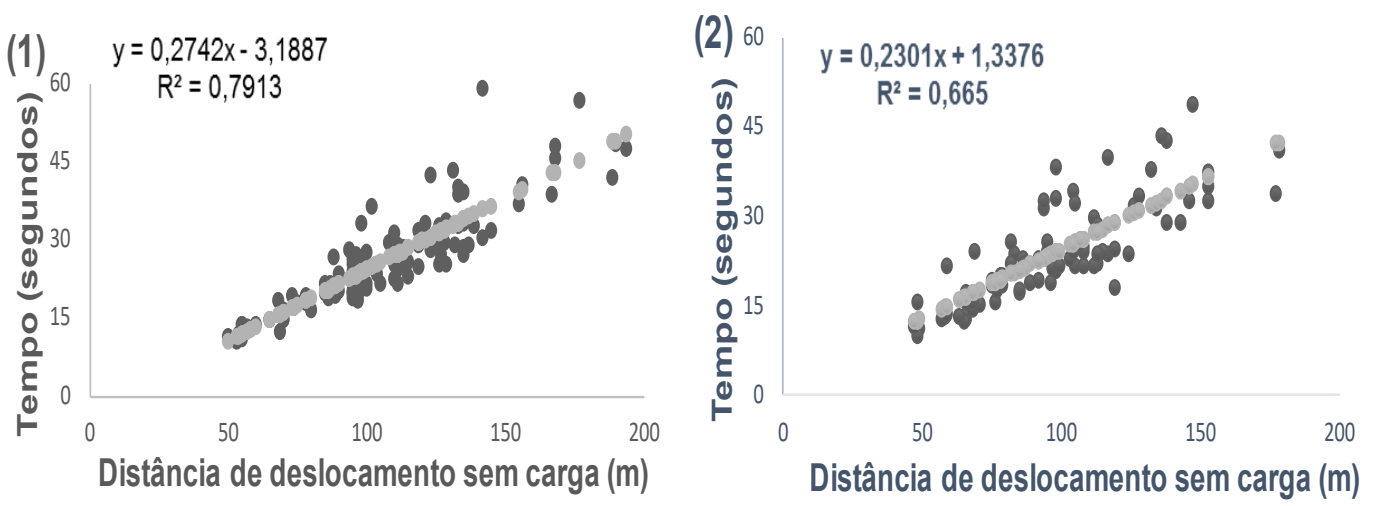

Figura 2. Modelagem do tempo sem carga do skidder para os povoamentos (1) e (2) em função da distância de deslocamento.

A modelagem do deslocamento com carga evidenciou aumento do tempo com o aumento da distância de arraste (Figura 3). As áreas mais produtivas (povoamento 2) proporcionaram maior inclinação da equação, demandando maior tempo para realização do arraste. Em contrapartida, as árvores de menor volume (povoamento 1), proporcionaram menor peso e melhor desempenho no arraste de madeira. 
(1)

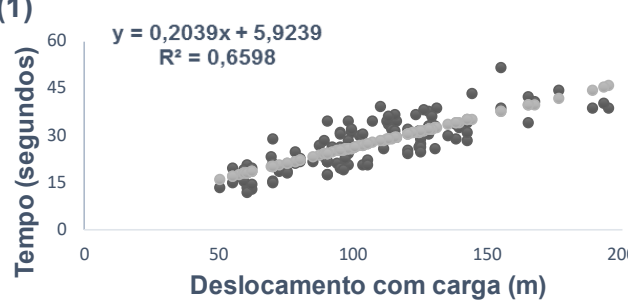

(2)

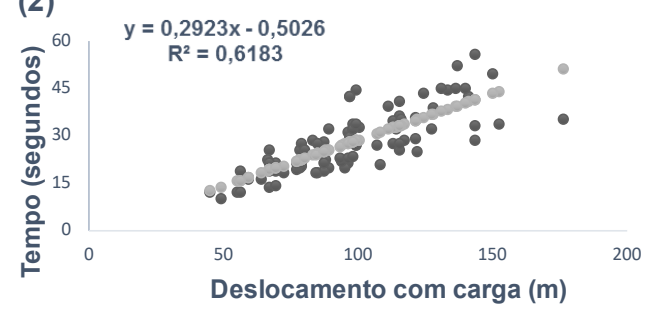

Figura 3. Modelagem do tempo com carga do skidder para os povoamentos (1) e (2) em função da distância de deslocamento.

Os tempos de deslocamento com carga para ambos povoamentos foram maiores do que os tempos de deslocamento vazio, sendo estes elementos de maior consumo de tempo do ciclo operacional, resultado similar ao encontrado por Lopes et al. (2017). Entretanto, os menores volumes por árvore neste estudo resultaram em menor tempo do ciclo operacional em comparação aos encontrados por Lopes et al. (2017).

Os percentuais de deslocamento com carga foram de 36,49\% e 40,36\% para os povoamentos 1 e 2, respectivamente. Moreira (2000) ao avaliar um skidder Caterpillar 525, encontrou uma composição percentual do ciclo operacional similar ao povoamento 1 e diferente do povoamento 2 da presente pesquisa. O maior volume médio das árvores no povoamento 2 reduziu as velocidades operacionais em decorrência do maior peso e resistência ao deslocamento (Tabela 3).

Tabela 3. Médias das velocidades operacionais sem e com carga do skidder operando nos povoamentos (1) e (2).

\begin{tabular}{|c|c|c|}
\hline \multirow{3}{*}{ Componentes do ciclo operacional do Skidder } & \multicolumn{2}{|c|}{ Velocidade operacional $\left(\mathrm{m} \mathrm{s}^{-1}\right)$} \\
\hline & \multicolumn{2}{|c|}{ Povoamentos } \\
\hline & (1) $0,257 \mathrm{~m}^{3} \mathrm{arv}^{-1}$ & (2) $0,329 \mathrm{~m}^{3} \mathrm{arv}^{-1}$ \\
\hline Deslocamento sem carga & $4,23 \mathrm{a}$ & $4,22 \mathrm{a}$ \\
\hline Deslocamento com carga & $3,91 \mathrm{a}$ & $3,65 b$ \\
\hline
\end{tabular}

(*) Médias seguidas por uma mesma letra, na linha, não diferem entre si pelo teste "t", a 5\% de probabilidade

A produtividade do skidder no povoamento $1\left(94,55 \mathrm{~m}^{3} \mathrm{~h}^{-1}\right)$ foi menor que no povoamento $2\left(126,71 \mathrm{~m}^{3} \mathrm{~h}^{-1}\right)$, considerando a distância média de extração de 109 m (Tabela 4), sendo 34\% superior no povoamento 2 (volume por árvore de 0,329 $\mathrm{m}^{3}$ ), em relação ao povoamento 1 (volume por árvore de 0,237 $\mathrm{m}^{3}$ ).

Tabela 4. Médias de produtividade efetiva do skidder em função do volume médio individual.

\begin{tabular}{ccc} 
Povoamentos & Volume médio individual por árvore & Produtividade efetiva $\left(\mathbf{m}^{\mathbf{3}} \mathbf{h}^{-1}\right)$ \\
\hline 1 & 0,257 & $94,55 \mathrm{a}^{*}$ \\
2 & 0,329 & $126,71 \mathrm{~b}$
\end{tabular}

(*) Médias seguidas por uma mesma letra, na coluna, não diferem entre si pelo teste "t", a 5\% de probabilidade.

A produtividade do skidder declinou com o aumento distâncias de extração nos dos povoamentos avaliados (Figura 4). Uma maior distância a ser percorrida implica em maior gasto de tempo no deslocamento da máquina e, em consequência, uma redução da produtividade de operação (Malinovski et al., 2006). A maior velocidade de deslocamento deste estudo evidenciou maior produtividade para as menores distâncias de extração em relação aos resultados Lopes et al. (2017). 

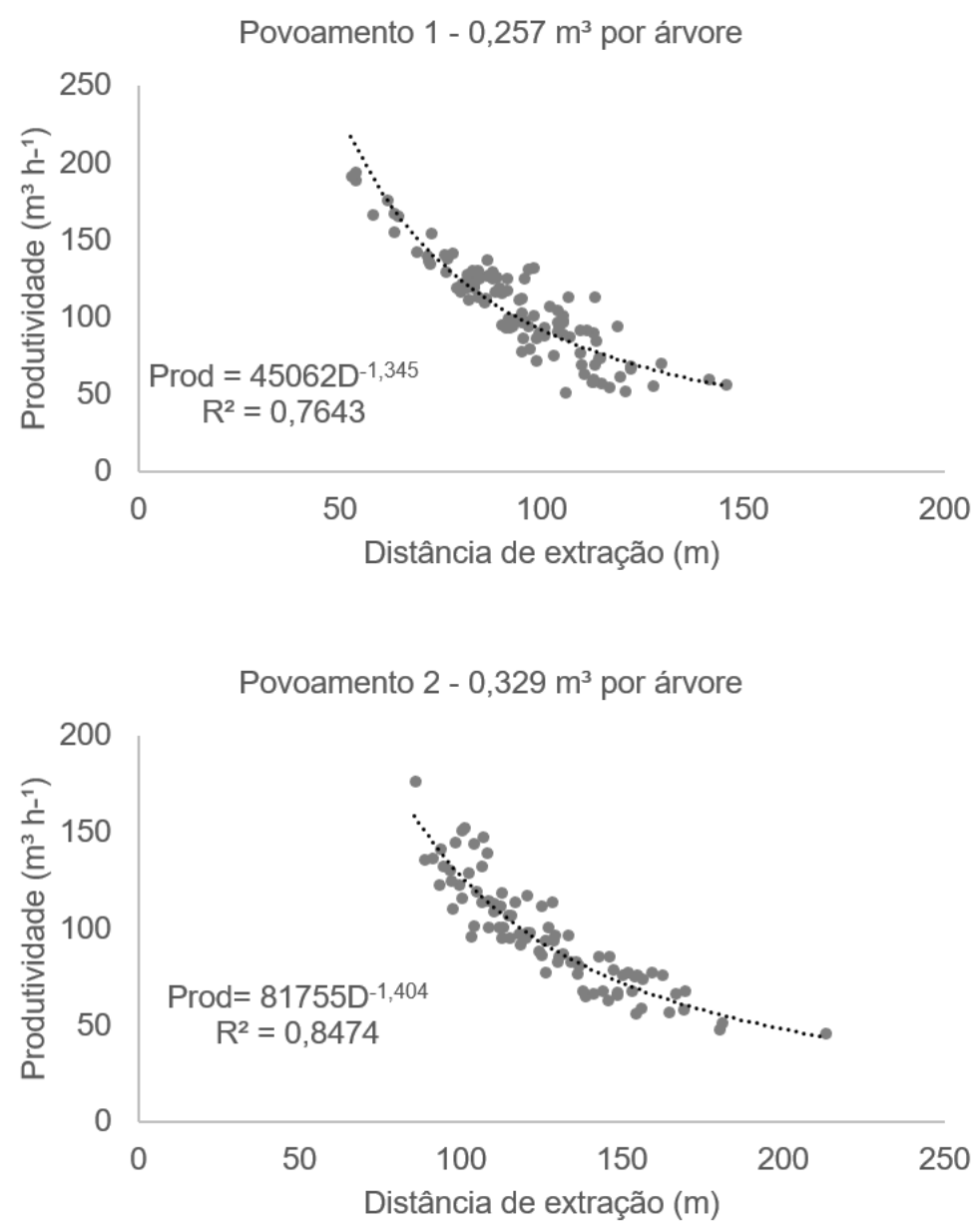

Figura 4. Modelagem da produtividade efetiva (Prod) do skidder em função da distância de extração (D) dos povoamentos 1 e 2 . $R^{2}=$ Coeficiente de determinação.

O aumento do volume das árvores resultou em maior produtividade do skidder, corroborando com os resultados encontrados por Araújo (2014), na comparação de distâncias similares a deste estudo. Na modelagem da produtividade associada a $230 \mathrm{~m}$ de distância de extração observa-se similaridade com os resultados de Fiedler et al. (2008). Entretanto, a produtividade foi superior aos resultados obtidos por Miyajima el al. (2017) e Rocha et al. (2009), justificada pela maior máquina, conferindo maior capacidade de carga, nas condições deste estudo.

A disponibilidade mecânica do skidder foi $86,4 \%$. Esse valor foi atribuído ao planejamento da empresa que realiza manutenções preventivas a cada 250 horas, evitando manutenções corretivas demoradas, o que configura a antecipação a possíveis falhas mecânicas, além da máquina apresentar 6.572 horas, aproximadamente $32,9 \%$ da vida útil, o que resulta menor frequência de problemas mecânicos.

Em relação ao indicador eficiência operacional o skidder atingiu o índice de $76,3 \%$, isso se deve ao baixo percentual de interrupções operacionais, sendo o valor considerado similar ao de Lopes et al. (2017).

O custo operacional do skidder Catepillar, modelo 555 D, foi de US\$136,25 por hora efetiva de trabalho (cotação $U \$ 1,00=R \$ 5,387$ cotado no dia 05/02/21), sendo 16,64\% correspondente aos custos fixos e $83,36 \%$ corresponderam aos custos variáveis. Os custos de combustíveis foram os mais expressivos (US\$38,45 he ${ }^{-1} ; 28,22 \%$ ) e os custos de manutenção e reparos foram os maiores custos horários do skidder (Figura 5). 


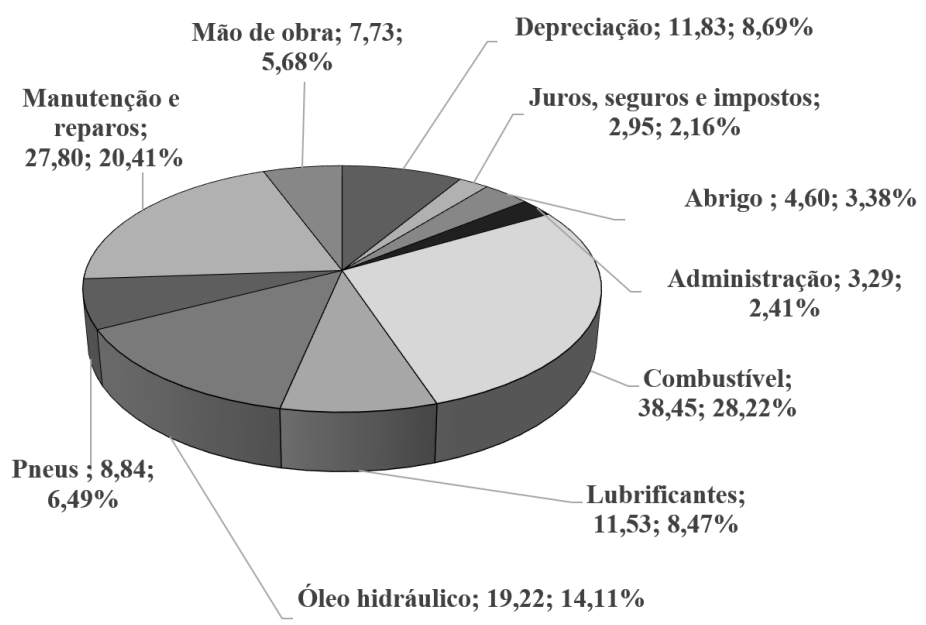

Figura 5. Composição do custo operacional do skidder Catepillar, modelo 555 D, em dólares por hora efetiva trabalhada (US\$ he-1) e porcentagem (\%).

Santos (2016) avaliando um skidder, modelo $748 \mathrm{H}$, da marca John Deere, encontrou um custo de US\$125,26 he ${ }^{-1}$, sendo 79,04\% correspondente aos custos variáveis. Os maiores valores deste estudo se devem ao fato de a máquina avaliada ser mais robusta, de maior porte, maior potência, elevando os custos de combustíveis, manutenção e óleo hidráulico. $O$ mesmo caso foi observado na comparação aos estudos de Miyajima et al. (2017) e Moreira (2000).

O custo de produção para a distância média de 109 metros de extração foi de US\$1,44 e US $\$ 1,07 \mathrm{~m}^{3}$ para os povoamentos 1 e 2 , respectivamente. Os resultados mostraram que o custo de produção aumentou com o incremento da distância de extração (Figura 6). Já o efeito do maior volume médio por árvore (Povoamento 2 ) resultou em maiores produtividades, ou seja, à medida que aumenta o volume por árvore, o custo tende a diminuir, fato observado no trabalho de Moreira (2000).
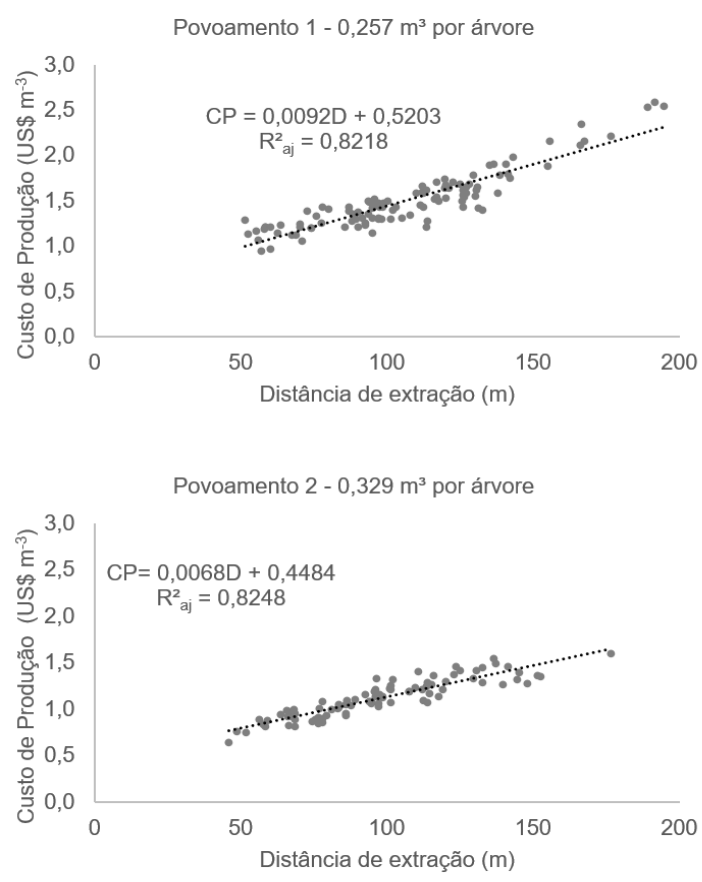

Figura 6. Modelagem do custo de produção efetivo (CP) do skidder em função da distância de extração (D) nos dois povoamentos florestais avaliados. $\mathrm{R}_{\mathrm{aj}}^{2}=$ Coeficiente de determinação ajustado. 
No contexto da presente pesquisa, observou que a maior distância de arraste proporcionou menor rendimento, principalmente devido ao maior tempo para realização das etapas do ciclo operacional "viagem sem carga" e "viagem com carga" (arraste). Tais etapas representam um percentual significativo do ciclo operacional total, culminando de forma decisiva para a performance da operação.

O povoamento mais produtivo apresentou menor custo de produção, uma vez que neste cenário a máquina extraia um volume maior por ciclo que, apesar de proporcionar menor velocidade de tráfego para o skidder em relação ao povoamento menos produtivo, condicionou uma maior eficiência no que se refere ao volume de madeira empilhado nas margens das estradas, por hora efetiva de trabalho. Assim, o maior rendimento (atrelado ao volume de madeira extraída por hora efetiva), contribuiu para que o custo fosse menor nesta unidade produtiva.

Os custos de produção para o skidder Fernandes et al. (2009), Miyajima el al. (2017) e Lopes et al. (2009) também evidenciaram a tendência de aumento do custo de produção quando do aumento da distância de arraste e o melhor desempenho ocorreu em menores distâncias, entretanto, os valores foram inferiores ao encontrado neste estudo. Estas diferenças estão relacionadas a maior cotação do Dólar em relação ao Real, maiores valores de combustível e pelo volume por árvore.

\section{CONCLUSÕES}

O aumento da distância de extração e os povoamentos de maiores volumes proporcionam aumento do tempo do ciclo operacional. Os elementos do ciclo operacional "arraste" e "deslocamento com carga" resultam em maior demanda de tempo.

Os custos de operacionais foram expressivos, entretanto, a operação com uma máquina robusta, foi capaz de reduzir os custos de produção. Os custos de manutenção, combustível, lubrificante e depreciação foram os mais representativos na composição do custo operacional total do skidder.

A modelagem demostra que a redução da distância de extração e os maiores volumes de madeira proporcionam maiores produtividades e menores custos de produção do skidder, conforme demostrado para as condições dessa pesquisa. Os resultados mostraram-se de grande contribuição para o planejamento, indicando a relação das variáveis avaliadas com a sustentabilidade da colheita florestal.

\section{REFERÊNCIAS BIBLIOGRÁFICAS}

Araújo, L. C. (2014). Influência de corredores ecológicos na produtividade de máquinas de colheita florestal. (Dissertação de mestrado). Universidade Federal dos Vales do Jequitinhonha e Mucuri, Diamantina.

Alvares, C. A., Stape, J. L., Sentelhas, P. C., Moraes, G., Leonardo, J., \& Sparovek, G. (2013). Koppen's climate classification map for Brazil. Meteorologische Zeitschrift, 22(6), 711-728. http://dx.doi.org/10.1127/0941-2948/2013/0507.

American Society of Agricultural Engineers - ASAE. (2001). Standards 2001: machinery, equipment and buildings: operating costs (226 p.). lowa.

Barnes, R. M. (1977). Estudos de movimentos e de tempos: projeto e medida do trabalho (6. ed.). São Paulo: Edgard Blucher.

Birro, M. H., Machado, C. C., Souza, A. P., \& Minetti, L. J. (2002). Avaliação técnica e econômica da extração de madeira de eucalipto com "track-skidder" em região montanhosa. Revista Árvore, 28(2), 207-217. http://dx.doi.org/10.1590/S0100-67622002000500001.

Caterpillar. (2015). 525D/535D/545D/555D Wheel Skidders. Recuperado em 12 de dezembro de 2018, de https://s7d2.scene7.com/is/content/Caterpillar/C10307331

Fernandes, H. C., Lopes, S. E., Teixeira, M. M., Minette, L. J., Rinaldi, P. C. N., \& Bernardes, A. M. (2009). Avaliação das características técnica e econômica de um sistema de colheita florestal de árvores inteiras. Scientia Forestalis, 37(83), 225-232. Recuperado em 18 de abril de 2020, de https://www.ipef.br/publicacoes/scientia/nr83/cap01.pdf 
Fiedler, N. C., Rocha, E. B., \& Lopes, E. S. (2008). da S. Análise da produtividade de um sistema de colheita de árvores inteiras no norte do estado de Goiás. Revista Floresta, 38(4), 577-586. http://dx.doi.org/10.5380/rf.v38i4.13153.

Indústria Brasileira de Árvores - IBÁ. (2019). Anuário estatístico da IBÁ 2019: ano base 2018 (80р.). Brasília, DF. Recuperado em 18 de abril de 2020, de https://iba.org/datafiles/publicacoes/relatorios/iba-relatorioanual2019.pdf

Leite, E. S., Fernandes, H. C., Minette, L. J., Souza, A. P., Leite, H. G., \& Guedes, I. L. (2014). Modelagem do desempenho da extração de madeira pelo "forwarder". Revista Árvore, 38(5), 879-887. http://dx.doi.org/10.1590/S0100-67622014000500012.

Lordelo, J. T. B. (Março-Maio, 2012). As inovações inseridas na colheita. Revista Opiniões, p.20. Recuperado em 22 de outubro de 2020, de https://florestal.revistaopinioes.com.br/revista/leitura/online/inovacoes-tecnologicas-no-plantiocolheita-e-trans/.

Lopes, E. S. \& Diniz, C. C. C. (2015). Produtividade do trator florestal chocker skidder na extração de madeira em terrenos declivosos. Revista Floresta, 45(3), 625-634. http://dx.doi.org/10.5380/rf.v45i3.36409.

Lopes, E. S., Oliveira, D., Rodrigues, C. K., \& Drinko, C. H. (2017). Variables influencing working time and skidder productivity in wood extraction. Nativa, 5(4), 298-302. http://dx.doi.org/10.5935/23187670.v05n04a12.

Lopes, S. E., Fernandes, H. C., Minette, L. J., Silveira, J. C. M., \& Rinaldi, P. C. N. (2009). RInaldi, P. C. N. Avaliação técnica e econômica de um "skidder" operando em diferentes produtividades e distâncias de extração. Ciência e Agrotecnologia, 33(6), 1621-1626. http://dx.doi.org/10.1590/S141370542009000600023.

Machado, C. C., \& Lopes, E. S. (2008). Planejamento. In C. M. Cardoso (Ed.). Colheita florestal (pp. 185230). Viçosa: Editora UFV.

Machado, C. C., Silva, E. N., Pereira, R. S., \& Castro, G. P. (2014). O setor florestal brasileiro e a colheita florestal. In C. M. Cardoso (Ed.). Colheita florestal (pp. 15-45). Viçosa: Editora UFV.

Malinovski, R. A., Malinovski, R., Malinovski, J. R., \& Yamaji, F. M. (2006). Análise das variáveis de influência na produtividade das máquinas de colheita de madeira em função das características físicas do terreno, do povoamento e do planejamento operacional florestal. Revista Floresta, 36(2), 169-182. http://dx.doi.org/10.5380/rf.v36i2.6459.

Miyajima, R. H., Tonin, R. P., Fenner, P. T., \& Simões, D. (2017). Análise quantitativa do risco técnicoeconômico de um trator florestal skidder. BIOFIX Scientific Journal, 2, 12. http://dx.doi.org/10.5380/biofix.v2i0.56339.

Moreira, F. M. T. (2000). Análise técnica e econômica de subsistemas de colheita de madeira de eucalipto em terceira rotação (Dissertação de mestrado). Universidade Federal de Viçosa, Viçosa.

Pereira, A. L. N., Lopes, E. D. S., \& Dias, A. N. (2015). Análise técnica e de custo do feller buncher e skidder na colheita de madeira em diferentes produtividades do povoamento. Ciência Florestal, 25(4), http://dx.doi.org/10.5902/1980509820659.

Robert, R. C. G., Silva, F. A. P. C., Rocha, M. P., Amaral, E. J., \& Guedes, I. L. (2013). Avaliação do Desempenho Operacional do harvester 911.3 X3M em Áreas Declivosas. Revista Floresta e Ambiente, 20(2), 183-190. http://dx.doi.org/10.4322/floram.2013.011.

Rocha, E. B., Fiedler, N. C., Alves, R. T., Lopes, E. S., Guimarães, P. P., \& Peroni, L. (2009). Produtividade e custos de um sistema de colheita de árvores inteiras. Cerne, 15(3), 372-381.

Santos, D. W. F. D. N. (2016). Avaliação técnica e econômica de um sistema alternativo de colheita florestal de toras curtas (Dissertação de mestrado). Universidade Federal de Viçosa, Viçosa.

Santos, P. H. A., Souza, A. P., Marzano, F. L. C., \& Minette, L. J. (2013). Produtividade e custos de extração de madeira de eucalipto com clambunk skidder. Revista Árvore, 37(3), 511-518. http://dx.doi.org/10.1590/S0100-67622013000300014.

Silva, M. L., Miranda, G. M., Cordeiro, S. A., \& Leite, E. S. (2014). Custos. In C. C. Machado (Ed.), Colheita florestal (pp. 254-287). Viçosa: Editora UFV.

Simões, D. (2008). Avaliação econômica de dois sistemas de colheita florestal mecanizada de eucalipto. (Dissertação de mestrado). Universidade Estadual Paulista, Botucatu.

Simões, D., \& Fenner, P. T. (2010). Avaliação técnica e econômica do forwarder na extração de madeira em povoamento de eucalipto de primeiro corte. Revista Floresta, 40(4), 711-720. http://dx.doi.org/10.5380/rf.v40i4.20323. 
Superintendência de Estudos Econômicos e Sociais da Bahia - SEl. (2010). Estatística dos municípios baianos (Vol. 1, 414 p.). Salvador.

Contribuição dos Autores: APSB: Conceituação, Curadoria de Dados, Análise Formal, Validação, Escrita - Primeira Redação, Escrita - Revisão e Edição; LCF: Supervisão, Validação, Visualização, Administração do Projeto; ESL: Conceituação, Curadoria de Dados, Análise Formal, Metodologia, Escrita - Primeira Redação, Escrita - Revisão e Edição; DSL: Curadoria de Dados, Análise Formal, Metodologia; Investigação; LFS: Análise Formal, Metodologia, Escrita - Primeira Redação; BSS: Curadoria de Dados, Análise Formal, Recursos, Conceituação; JCS: Curadoria de Dados, Análise Formal, Metodologia 